\title{
Experimental investigation of heat transfer performance in a triangular pitch plain tubes bundle
}

\author{
[ Shehryar Ishaque, Man-Hoe Kim ]
}

\begin{abstract}
In the present study Nu correlation of tube side for triangular pitch plain tubes bundle is proposed. The performance of the current heat exchanger is investigated experimentally in a single phase. Ten different experiments were conducted for different flow rates in order to study the effect of different parameters on heat transfer coefficient correlation. Hot inlet temperature was kept at $25^{\circ} \mathrm{C}$ whereas, cold inlet temperature was kept at $15^{\circ} \mathrm{C}$. Reynolds number was varied from 2300-20,000. Matlab code for modified Wilson plot method was also developed to overcome the assumption of Reynolds exponent in Wilson plot method. All the required parameters like temperature, flow rate and pressure were calculated using calibrated instruments. The tube-side Nu correlation was proposed and compared with existing correlations. The maximum difference came out to be $3.8 \%$ and $5.7 \%$ with Seider and Tate and Dittus-Boelter correlations respectively whereas, difference with Gnielinski correlation in turbulent region was less than $12 \%$ but for transition region it was more than $20 \%$.
\end{abstract}

Keywords- Plain tubes bundle, Wilson plot method, $\mathrm{Nu}$ correlation, Modified Wilson plot method.

\section{Introduction}

A lot of work have been done in the past in order to study the heat transfer characteristics and pressure drop performance of different heat exchanger geometries. Several data have been published for different types and arrangement of tubes. The performance of heat exchanger depends on heat transfer coefficient, pressure drop and flow rate.

Many researchers used Wilson plot method or modified Wilson plot method which are being excellent practical methods for the development of shell side or tube side heat transfer correlations. Most of them used water in both streams.

Saera et al. [1] summarized some of the correlations developed by Williams and Katz [2] using plain and finned tube bundles. Water, oil, steam and glycerine were used as fluids. Some researchers used enhanced titanium geometries, some used flooded evaporators and some used tube-in-tube heat exchangers for single and two phase flow. Young and Wall [3] used it in finned and bare duplex tubes.

Shehryar Ishaque, PhD Scholar

Dept. of Mechanical Engineering, Kyungpook National University South Korea

Man Hoe Kim, Professor

School of Mechanical Engineering, Kyungpook National University South Korea
Ribatski and Thome [4] used Wilson plot method to study heat transfer performance for smooth and enhanced tubes. Briggs and Young [5] used modified Wilson plot method in such a way that three unknowns $C_{i}, C_{o}$ and Re exponent were calculated by the modification done to the Wilson plot. They used single phase water as a fluid with turbulent flow on both tube side as well as annulus side. De Vos [6] utilized the same method for tube-in-tube heat exchanger with fluted internal tube to find the heat transfer resistances. Hasim et al. [7, 8] used Wilson plot technique and investigated twisted tape inserts [7] and ribbed tubes with wire [8]. Water was used as a cooling and heating fluid in both cases. Zheng et al. [9] analysed heat transfer characteristics using Wilson plot method in shell and flooded evaporator. Ammonia was used as a refrigerant in the following experiments. Experiments were conducted on plain tubes bundle and empirical correlation was developed. Young et al. [10-13] have investigated bimetal tubes [10], finned tubes [11] and fouling in different geometries of shell and tube heat exchangers $[12,13]$. Condensation of R-22 was investigated by Cheng et al. [14]. They used Dittus Boelter correlation with water as a fluid in six different enhanced tubes [15]. Wilson plot method was used in calculating heat transfer coefficient. Similarly Kumar et al. [16] have done analysis using Sieder-Tate correlation on horizontal cooper tubes.

Most of the researchers used modified Wilson plot including Coetzee et al. [17], Louw and Meyer [18], Da Veiga and Willem [19], Rennie and Raghavan [20], Yang and Chiang [21], Smit [22], Wang et al. [23], Webb and Zhang [24], Yang and Webb [25] and Kim et al. [26] in high-fin, microfin and twisted tape insert tubes.

It should be noted that all of the previously reported studies provide heat transfer characteristics of different geometries, flow conditions or experimental setup. If accurate and reliable correlations for $\mathrm{Nu}$ and pressure drop for direct expansion evaporators are available, only then the heat transfer enhancement characteristics of such evaporators could be used in the industrial applications. Primary aim of the current research is to study the heat transfer performance of triangular pitch plain tubes bundle. This evaporator is basically designed by ISOTHERM.INC for ammonia. So main focus of this investigation is on developing a single phase heat transfer correlation on tube side which can be used for further research on similar heat exchangers using ammonia. Past studies have not investigated such type of shell and tube heat exchanger which can be used as a direct expansion evaporator using ammonia with the present plain tubes bundle arrangement. 
Proc. of Sixth International Conference On Advances in Civil, Structural and Mechanical Engineering -ACSM 2017 Copyright (C) Institute of Research Engineers and Doctors, USA .All rights reserved.

ISBN: 978-1-63248-118-4 doi: 10.15224/ 978-1-63248-118-4-27

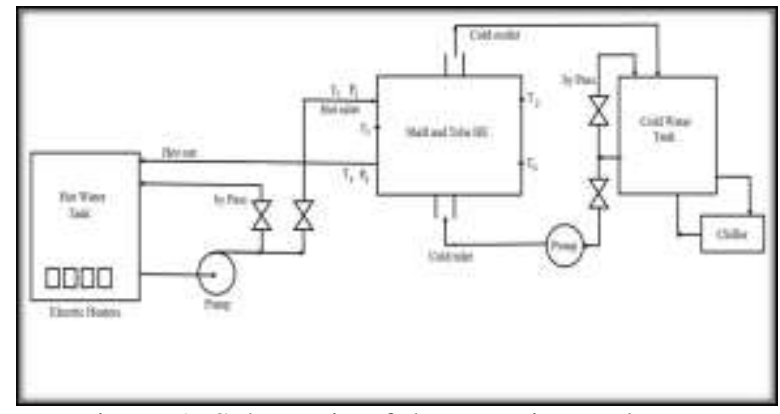

Figure 1. Schematic of the experimental setup

\section{Experimentation}

\section{A. Experimental setup}

Experiments were performed on a triangular pitch plain tubes bundle with four passes. The two water streams were arranged in a cross flow. Schematic of the current experimental setup is shown in Fig. 1. The setup can be divided into hot and cold water loops.

Hot water loop comprises of hot water tank and a pump. The hot water circulates through heat exchanger with the help of motor of $2.2 \mathrm{~kW}$ capacity with maximum speed of $1,440 \mathrm{rpm}$. A bypass valve is connected to adjust the flow rate of the hot water side. The hot water tank has 150US gallons storing capacity with 8 electric heaters immersed in it. Power inverter is installed on the pump motor to control the speed with the help of which flow rate is adjusted besides supply valve and bypass valve. The desired amount of hot water passes through the tubes of the heat exchanger and the excess hot water returned back to hot water tank through a by-pass valve.

All the piping, hot water tank, heat exchanger and cold water tank are well insulated by polyurethane foam with aluminium foil in order to reduce the exchange of heat with atmosphere.

The cold water tank has the capacity of 35US gallons. The fresh water provided to the chiller is cold by 2Ton of refrigeration chiller which uses R22 as a refrigerant. Sensors are attached in the chiller through which cold water inlet temperature is set. Cold water circulates with the help of pump. Temperature data is recorded in the computer through data logger.

\section{B. Heat exchanger geometry}

In the present study triangular pitch plain tubes bundle with four passes is tested. Some of the geometric features are given in Table 1. The Pro-E model is shown in Fig. 2.

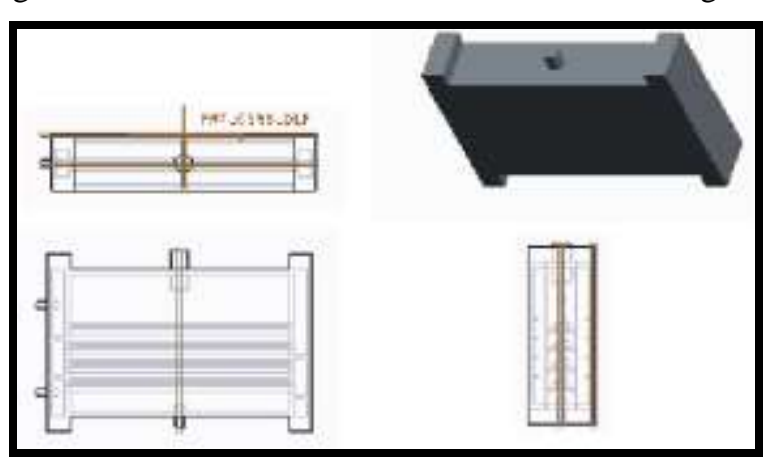

Figure 2 Pro-E model of the heat exchanger
TABLE 1 Dimensions of the different components

\begin{tabular}{|c|c|}
\hline Material of the tube & SA-179 \\
\hline Tube Inner diameter & $0.0169 \mathrm{~m}$ \\
\hline Tube outer diameter & $0.01905 \mathrm{~m}$ \\
\hline Length of the single pass & $0.6604 \mathrm{~m}$ \\
\hline Number of passes & 4 \\
\hline Tubes per bundle & 3 \\
\hline Material of the shell & SA179 \\
\hline Length of the shell & $0.5969 \mathrm{~m}$ \\
\hline Width of the shell & $0.0508 \mathrm{~m}$ \\
\hline Height of the shell & $0.4572 \mathrm{~m}$ \\
\hline Thickness of the shell & $0.0175 \mathrm{~m}$ \\
\hline
\end{tabular}

\section{Instrumentation}

(RTD's) are installed at inlet and outlet of the shell and the tubes to measure the temperature at different points as shown in Fig.1. Type and specifications are given in Table 2. These are further linked with the data logger which has a graphic representation and LCD display with 16 channel inputs. Differential pressure transmitters (BCM sensors) were installed at inlet and exit of the shell and the tubes for both cold and hot water streams respectively. Type and specifications of the BCM sensors are given in Table 3.

\section{Experimental Procedure}

The heaters, pump, chiller and data logger were turned on such that both the hot and cold streams started circulation and the data logger showed different values for temperatures at different points. Some heaters were turned in order to get hot inlet temperature of $25^{\circ} \mathrm{C}$ whereas, cold inlet temperature was set in the chiller to $15^{\circ} \mathrm{C}$. Volume flow rate of cold fluid side was kept fixed whereas, volume flow rate of hot water side was varied for each experiment. The cold side flow rate was controlled by supply valve and a bypass valve whereas, flow rate of hot water side was controlled by power inverter and supply valve. Volume flow rates on both sides were measured by calibrated cylinder and a stop watch method. When the variation in temperature was within $\pm 0.2^{\circ} \mathrm{C}$, the data was recorded.

Once the flow rate and temperature were set the system was given enough time to attain the steady state condition. The best 20 minutes were noted out of the data recorded for about one hour for each experiment. Outlet temperature and pressure were also noted for each flow rate. The hot water side flow rate was changed for each experiment and the same procedure was repeated.

TABLE 2 Specifications of RTD's

\begin{tabular}{|c|c|}
\hline Type & Three wires Pt-100 \\
\hline Insulated by & $\begin{array}{c}\text { Sheathed class "A" of } \\
\text { stainless steel }\end{array}$ \\
\hline Manufactured by & TC limited of UK \\
\hline Uncertainty & $\pm 0.1^{\circ} \mathrm{C}$ \\
\hline Diameter of the sheath of the RTD & $6 \mathrm{~mm}$ \\
\hline Length of the sheath of the RTD & $100 \mathrm{~mm}$ \\
\hline
\end{tabular}


TABLE 3 Specifications of BCM sensors

\begin{tabular}{|l|l|}
\hline Type & STK 131 \\
\hline Power & $12-36 \mathrm{VDC}$ \\
\hline Range & $0-69 \mathrm{k} \mathrm{Pa}$ \\
\hline Output & $4-20 \mathrm{~mA}$ \\
\hline Accuracy & $0.1 \%$ \\
\hline
\end{tabular}

\section{Data Reduction}

In order to find the heat transfer coefficient Wilson plot method [27] is used, varying the hot water side flow rate and keeping the cold water side flow rate constant. Temperature, pressure and flow rate at different points for both streams were measured by calibrated instruments. Properties were determined at average temperatures from the standard tables available. The correction factor ' $F$ ' in LMTD was taken from the graph [28] for cross flow shell and tube heat exchanger with ' $2,4,6 \ldots$ n' passes.

As there were assumptions of the exponents of the Re and Pr in Wilson plot method, so modification is done in the method to overcome the assumptions. The iterative procedure in Modified Wilson plot method is done using Matlab code which deduce the value of the exponent ' $\mathrm{m}$ ' of the Re. As a result of this modification $\mathrm{Nu}$ correlation is developed by only assuming the exponent of the Pr.

\section{Results and discussion}

Data is obtained for single phase flow (water to water) for triangular pitch tube bundle with four passes. Ten number of experiments were conducted with hot inlet temperature of about $25^{\circ} \mathrm{C}$ and cold inlet temperature of $15^{\circ} \mathrm{C}$. Cold water side flow rate was kept high in order to get high heat transfer coefficient on shell side and the hot water side flow rate was varied in each experiment. Re for hot water side was kept above 2300 whereas, Pr ranges from 6.2-6.5.

Wilson plot method was used as shown in Fig. 3. This gives the values of the constants $\mathrm{C}_{1}$ and $\mathrm{C}_{2}$, which are the intercept and the slope of Wilson plot. These values are further used in finding the coefficient ' $\mathrm{C}$ ' of $\mathrm{Nu}$ correlation.

The developed $\mathrm{Nu}$ correlation using modified Wilson plot method is given by (1). From which heat transfer coefficient correlation on hot water tube side can be predicted as given by (2).

$$
\begin{gathered}
\mathrm{Nu}=0.024 \operatorname{Re}_{\mathrm{h}}{ }^{0.8009} \operatorname{Pr}^{0.4} \\
\mathrm{~h}_{\mathrm{i}}=0.024 \mathrm{Re}_{\mathrm{h}}{ }^{0.8009} \operatorname{Pr}^{0.4}\left(\mathrm{k}_{\mathrm{h}} / \mathrm{d}\right)
\end{gathered}
$$

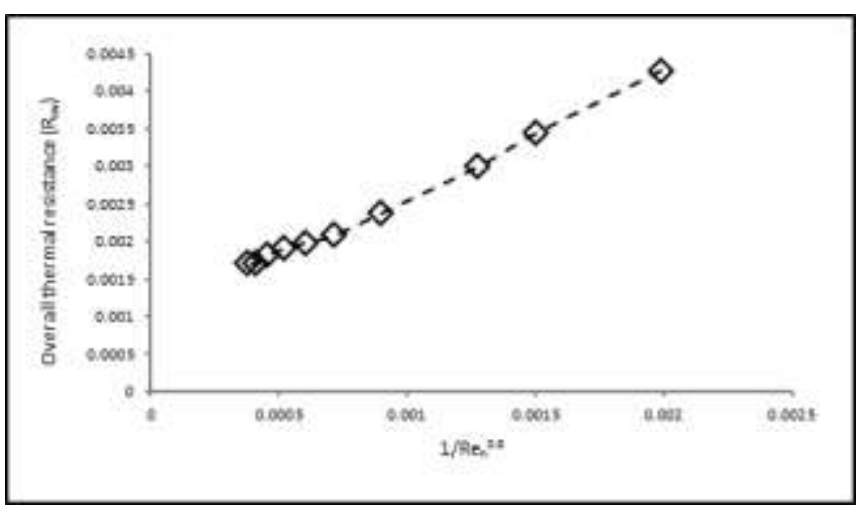

Figure 3 Wilson Plot

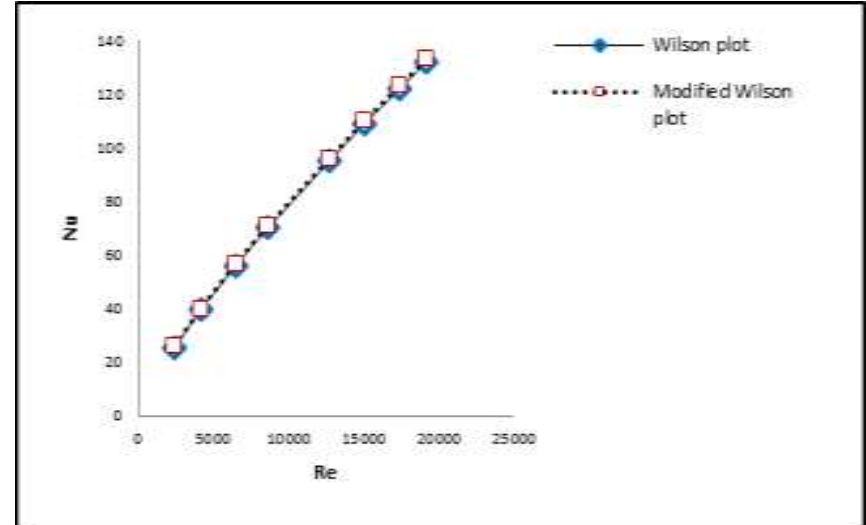

Figure 4 Effect of $\mathrm{Re}$ on $\mathrm{Nu}$

Effect of $\mathrm{Re}$ on $\mathrm{Nu}$ in a triangular pitch plain tubes bundle is shown in Fig. 4. The trend suggests that $\mathrm{Nu}$ increases linearly with $\mathrm{Re}$ as reported in the literature for different heat exchangers [29-31] but in each case the slopes varies due to different geometric and flow conditions.

Hot inlet temperature in each experiment was kept constant at about $25^{\circ} \mathrm{C}$ in all experiments but we also checked it for some other values and the correlation developed was not affected by changing its value. Hence, we concluded that the input temperatures do not affect the correlation.

The experimental $\mathrm{Nu}$ data of the present study is also compared with the existing correlations in the literature. Dittus-Boelter and Seider and Tate correlations are valid for Re greater than 10,000 and Pr ranges from 0.9 to 160 for Dittus-Boelter and 0.7 to 16700 for Seider and Tate correlation. Hence, comparison were made as shown in Fig. 5 with maximum difference observed were $5.7 \%$ for DittusBoelter correlation and 3.8\% for Seider-Tate correlation. On the other hand, Gnielinski correlation is valid in the ranges $3000 \leq \operatorname{Re} \leq 50,000$ and $0.5 \leq \operatorname{Pr} \leq 2000$. Proposed correlation was also compared with Gnielinski correlation in the same ranges and the difference came out to be more than $20 \%$ for transition range and less than $11 \%$ for turbulent region as shown in Fig. 5.

In Fig. 6 we can see that as the Re increases pressure drop increases. This is because of the fact that increasing Re will increase the turbulence. Due to turbulence, the pressure losses increases which results in more pressure drop. Similar trends were reported in literature for different types of geometries and flow conditions [33, 34]. Fig. 7 shows Darcy friction factor for plain tubes which varies within 0.0030.005 as in [35].

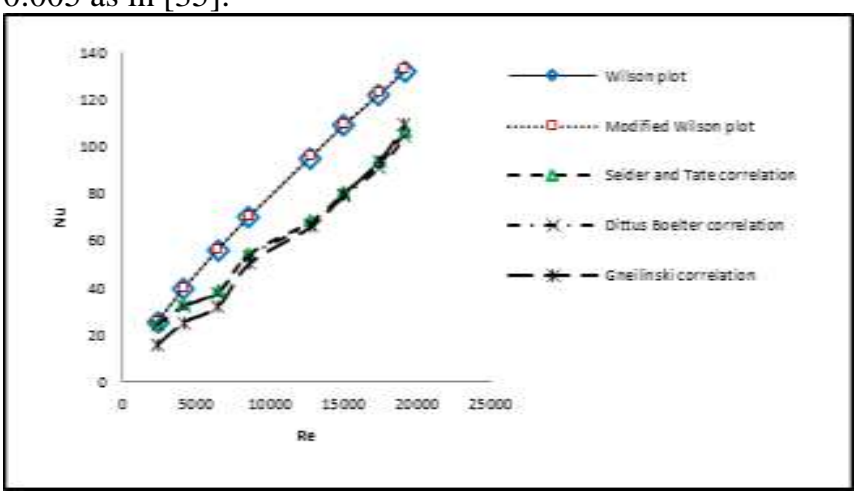

Figure 5 Comparison with existing correlations 


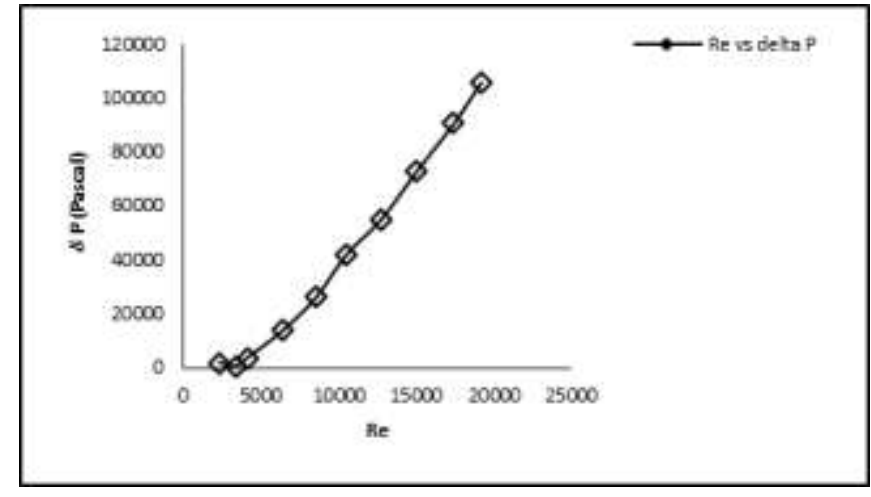

Figure 6 Effect of Re on pressure drop

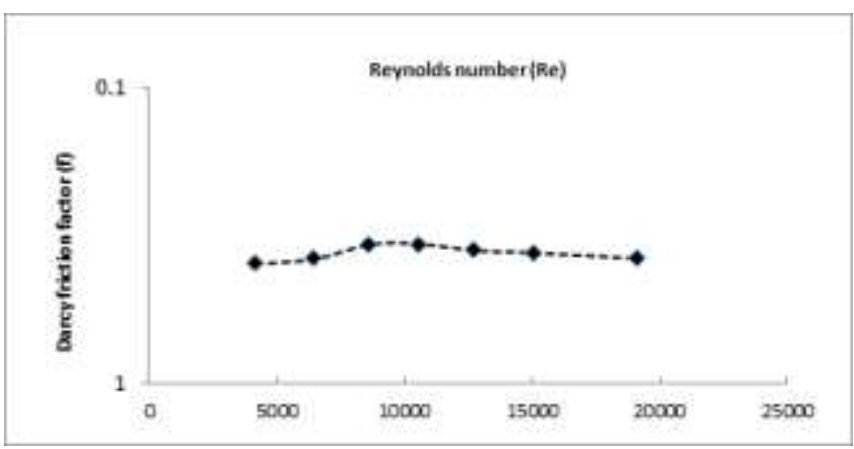

Figure 7 Effect of Re on Darcy friction factor

\section{v. Conclusions}

Ten experiments have been performed in order to investigate heat transfer characteristics of a triangular pitch plain tubes bundle with four passes. The input conditions were kept different in each experiment to investigate the effect of input conditions on heat transfer coefficient correlation and it has been concluded that heat transfer coefficient correlation is not affected by input conditions. $\mathrm{Nu}$ correlations have been proposed using Wilson plot and modified Wilson plot method which was in good agreement with existing correlations. The maximum difference came out to be $5.6 \%$ and $7.6 \%$ for Seider-Tate and Dittus Boelter correlations, respectively whereas, difference with Gnielinski correlation was less than $11 \%$ for turbulent region and more than $20 \%$ for transition region.

\section{Acknowledgment}

This work was supported partly by the Small and Mediumsized Company Technology Innovation Program (Grant No. S2222403) by the Ministry of Trade, Industry \& Energy of Korea. The authors gratefully acknowledge to Ahmad Abbas for his support during experimentation.

\section{Nomenclature}

$\mathrm{d} \quad$ Diameter of the tube, (m)

h Heat transfer coefficient, $\left(\mathrm{W} / \mathrm{m}^{2} . \mathrm{K}\right)$

$\mathrm{k}$ Thermal conductivity, (W/m.K)

L Tube length, (m)

M Mass flow rate, $(\mathrm{kg} / \mathrm{sec})$

$\mathrm{Nu} \quad$ Nusselt number,
Pr Prandtl number,

Q Heat load, $(\mathrm{kW})$

Re Reynolds number,

$\mathrm{T}$ Temperature, $\left({ }^{\circ} \mathrm{C}\right)$

$\mathrm{t}$ Tube thickness, $(\mathrm{m})$

$\mathrm{U} \quad$ Overall heat transfer coefficient, $\left(\mathrm{W} / \mathrm{m}^{2} . \mathrm{K}\right)$

V Velocity, $(\mathrm{m} / \mathrm{sec})$

LMTD Log mean temperature difference

\section{Subscript}

c cold water

h hot water

i inlet

o outlet

$\mathrm{t}$ tube

\section{References}

[1] Seara, J. F., Uh'1a, F. J., Sieres, J., and Campo, A., 2007. "A General review of the Wilson plot method and its modifications to determine convection coefficients in heat exchange Devices", Applied Thermal Engineering, Vol. 27, pp. 2745-2757.

[2] Williams R.B., Katz D.L., 1951. "Performance of finned tubes in shell and tube heat exchangers ”, Engineering Research Institute, University of Michigan.

[3] Young, E. H., and Wall, J. R., 1957. "Development of an Apparatus for the Measurement of Low Bond Resistance in Finned and Bare Duplex Tubing”, University of Michigan, Ann Arbor, Report no. 48.

[4] Ribatski G., and Thome J. R., 2006. "Nucleate Boiling Heat Transfer of R134a on Enhanced Tubes", Applied Thermal Engineering, Vol. 26, pp. 1018-1031.

[5] Briggs, D. E., and Young, E. H., 1969. "Modified Wilson Plot Techniques for Obtaining Heat Transfer Correlation for Shell and Tube Heat Exchangers", Journal of Heat Transfer, Vol. 5, pp. 51-56.

[6] De Vos, P. W., 2006. "Experimental Determination of the Forced Convective Boiling Heat Transfer Coefficients of R407C in Fluted Tubes, Master's thesis", University of the North West.

[7] Hasim F., Yoshida M., Miyashita H, 2003. "Compound heat transfer enhancement by a combination of ribbed tubes with coil inserts," Journal of Chemical Engineering of Japan Vol. 36, pp. 647-654.

[8] Hasim F., Yoshida M., Miyashita H., 2003. "Compound heat transfer enhancement by a combination of a helically ribbed tube with twisted tape inserts", Journal of Chemical Engineering of Japan, Vol. 36, pp. 1116-1122.

[9] Zheng X.J., Jin G.P., Chyu M.C., Ayub Z.H., 2006. "Boiling of ammonia/ lubricant mixture on a horizontal tube in a flooded evaporator with inlet vapor quality", Experimental Thermal and Fluid Sciences, Vol 30, pp. 223-231

[10] Young E.H., Weekman V.W., Balekjian G., Ward D.J., Godzak S.G., Grover S.S., 1954. "Effect of root wall thickness on bond resistance to heat transfer of bimetal tubes", Engineering Research Institute, University of Michigan, Report No 34.

[11] Young E.H., Katz M.L., Ward D.J., Wall J.R., Conroy W.F., Gutchess W.R., Terry C.T., 1956. "An investigation of the fouling of 19-finperinch admiralty tubes in three heat transfer units located at the Aurora Gasoline Company Refinery", Engineering Research Institute, University of Michigan, Report No. 44.

[12] Young E.H., Balekjian G., Ward D.J., Paquette A.J., Godzak S.G., Meckler M., Katz M.L., 1955. "The investigation of heat transfer and pressure drop of 11 fin per inch tubes and coils”, Engineering Research Institute, University of Michigan, Report No. 35.

[13] Young E.H., Terry C.T., Gonzalez L.O., Katz M.L., Ward D.J., 1956. "Fouling of an 11-fins-per-inch coil in an internal tankless water heater", Engineering Research Institute, University of Michigan, Report No. 42.

[14] Cheng W.Y., Wang C.C., Robert Hu Y.Z., Huang L.W., 1996. "Film condensation of HCFC-22 on horizontal enhanced tubes", International Communications in Heat and Mass Transfer, Vol. 23, pp. 79-90.

[15] Koichi Nakaso, Hiroki Mitani, Jun Fukai, 2015. "Convection heat transfer in a shell-and-tube heat exchanger using sheet fins for effective utilization of energy", International Journal of Heat and Mass Transfer, Vol. 82, pp. 581-587. 
[16] Kumar R., Varma H.K., Mohanty B., Agrawal K.N., 1998. "Augmentation of outside tube heat transfer coefficient during condensation of steam over horizontal copper tubes", International Communications in Heat and Mass Transfer, Vol. 25, pp. 81-91.

[17] Coetzee H., Liebenberg L., Meyer P.J., 2003. "Heat transfer and pressure drop characteristics of angled spiralling tape inserts in a heat exchanger annulus", Heat Transfer Engineering, Vol. 24, pp. 29-39.

[18] Louw W.I., Meyer J.P., 2005. "Heat transfer during annular tube contact in a helically coiled tube-in-tube heat exchanger", Heat Transfer Engineering, Vol. 26, pp. 16-21.

[19] Da Veiga W.R., Willem R.V., 2002. "Characteristics of a Semicircular Heat Exchanger Used in a Water Heated Condense Pump", Doctoral Theses, Rand Afrikaans University, Johannesburg, South Africa.

[20] Rennie T.J., Raghavan V.G.S., 2005. "Experimental studies of a doublepipe helical heat exchanger", Experimental Thermal and Fluid Sciences, Vol. 29, pp. 919-924

[21] Yang R., Chiang F.P., 2001. "An experimental study of heat transfer in curved pipe with periodically varying curvature for application in solar collectors and heat exchangers", Proceedings of the Intersociety Energy Conversion Engineering Conference, pp. 154-160.

[22] Smit F.J., 2002. "Condensation Coefficients of the Refrigerant Mixture R-22/R-142b in Smooth Tubes and During Enhanced Heat Transfer Configurations", Doctoral Thesis, Rand Afrikaans University, Johannesburg, South Africa.

[23] Wang C.C., Chiang C.S., Yu J.G., 1998. "An experimental study of in-tube evaporation of R-22 inside a $6.5-\mathrm{mm}$ smooth tube", International Journal of Heat and Fluid Flow, Vol. 19, pp. 259-269.

[24] Webb R.L., Zhang M., 1998. "Heat transfer and friction in small diameter channels", Microscale Thermophysical Engineering, Vol. 2 , pp. 189-202.

[25] Yang C.Y., Webb R.L., 1996. "Condensation of R-12 in small hydraulic diameter extruded aluminium tubes with and without microfins", International Journal of Heat and Mass Transfer, Vol. 39, 791800.

[26] Kim N.H., Cho J.P., Kim J.O., Young B., 2003. "Condensation heat transfer of R-22 and R-410A in flat aluminium multi-channel tubes with or without micro-fins", International Journal of Refrigeration, Vol. 26, pp. 830-839

[27] John W. Rose, "Heat-transfer coefficients, Wilson plots and accuracy of thermal measurements", Experimental Thermal and Fluid Science, Vol. 28, pp. 77-86, 2004

[28] Incropera F. P., DeWitt D. P., Bergman T. L., and Lavine A. S., 2007. "Fundamentals of Heat and Mass Transfer", $6^{\text {th }}$ ed., Wiley.

[29] Vahidinia. F., Miri, M., Farhad Vahidinia, and Mohadeseh Miri, 2015. "Numerical Study of the Effect of the Reynolds Numbers on Thermal and Hydrodynamic Parameters of Turbulent Flow Mixed Convection Heat Transfer in an Inclined Tube", Journal of Mechanical Engineering,Vol. 61, pp.669-679.

[30] Shiva Gupta, Abhishek Sharma, Kritika Singh \& Srivastava K.K. 2013. "Hydrodynamic and Thermal Study of Water in Narrow Copper Tube”, Indian Chemical Engineer, Vol. 55, pp. 294-306.

[31] Lia H., Kottkeb V., 1999. "Analysis of local shellside heat and mass transfer in the shell-and-tube heat exchanger with disc-and-doughnut baffles," International Journal of Heat and Mass Transfer, Vol. 42, pp. 3509-3521.

[32] Ramesh Shah K., Dusan Sekulic P., 2003. "Fundamentals of Heat Exchanger Design", John Wiley and Sons.

[33] Shweta Y Kulkarni, Jagadish, Manjunath, 2014. “Analysis comparing performance of a conventional shell and tube heat exchanger using Kern, Bell and Bell Delaware method," International Journal of Research in Engineering and Technology, pp. 2319-1163.

[34] Ratnesh Raj, Narender Shankar Lakshman, Yagnavalkya Mukkamala, 2015. "Single phase flow heat transfer and pressure drop measurements in doubly enhanced tubes", International Journal of Thermal Sciences, Vol. 88, pp. 215-227.

[35] Jukka Kiij arvi Lunowa, 2011. "Darcy Friction Factor Formulae in Turbulent Pipe Flow", Fluid Mechanics Paper, 110727.
About Author (s)

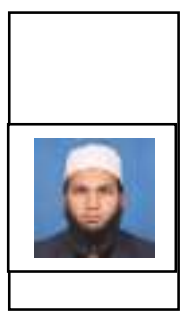

Shehryar Ishaque is a $\mathrm{PhD}$ scholar working under the supervision of Professor Man Hoe Kim in Heat transfer and Energy system Lab of Kyungpook National University, South Korea. He obtained his master degree from Ghulam Ishaq Khan Institite of Engineering Sciences and Technology, Topi, Swabi, Pakistan.

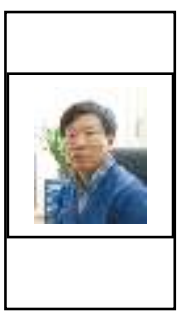

Dr. Man-Hoe Kim is a professor of School of Mechanical Engineering, Kyungpook National University (KNU). He received his Ph.D. degree in mechanical engineering from the KAIST in 1988. Prior to join in KNU in 2012, he worked for Samsung Electronics Co. for 15 years and worked at KAIST for 10 years as a Professor of Practice. His main research interests are in the areas of heat transfer and energy systems. 